a single line of change, and the differentiation of a specific type in two or more lines of change. The race of giants is formed-if I may again quote the pre-Darwinian expressions of the Laureate -by successive generations progressively mounting to higher things on the steps supplied by their own "dead selves." But this ladder-like succession of species in time differs in many respects from a tree-like multiplication of species in space; and the respect in which it differs most has reference to "the difficulty of the swamping effects of intercrossing." The transmutation of species in a single line of change is self-evidently capable of being effected by natural selection alone, because here free intercrossing among the uneliminated "fittest" is the very means whereby the transmutation is effected. But the tree-like multiplication of species (or Darwin's "divergence of character") is no less self-evidently incapable of being effected by natural selection alone; it is not so much as Iogically possible that any arborescence of species can take place unless natural selection is assisted by some form of isolation at the origin and throughout the development of every branch. The race of giants is evolved by intercrossing being "permitted between all the uneliminated individuals of each successive generation; but if at the same time a race of pygmies, another race of blacks, another of whites, \&c., are to be formed, it is a plain necessity of the case that intercrossing must be prevented between all these different races; else natural selection could not so much as begin to differentiate them.

This all-important distinction between what $\mathrm{Mr}$. Gulick has concisely termed "monotypic" and "polytypic" evolution is not observed by "Wallace and others," who are now said to have "amply dealt" with the "difficulty" in question. For they deal only with the case of monotypic evolution, with reference to which no one has been so foolish as to allege any difficulty ; and thus their whole treatment of the subject is irrelevant to the only difficulty which has been alleged, viz. the abstract impossibility of natural selection having ever effected polytypic evolution, or divergence of character, without the co-operation, in some form or another, of segregate breeding by the prevention of free intercrossing.

Oxford, April i 7 .

The Flying to Pieces of a Whirling Ring.

DR. LODGE appears to be still in error in making (p. 534), without qualification, the statement that "the dangerous tension will be set up in a straight portion of any endless band running in the direction of its length with the critical speed $\sqrt{\left(\frac{T}{\rho}\right) \text { : by }}$ the agency of the curved portions which necessarily exist somewhere." For the curved portions of such a band might run inside smooth guides which would supply the necessary centripetal pressure and relieve the band from all tension. Such an arrangement was in my mind when I wrote (p. 463) that the band need not be stretched to its breaking strain. It is true that Dr. Lodge began his original letter (on p. 439) by specifying a ring "not radially sustained," but he will, I feel sure, allow me to call attention to the fact that without a repetition of this qualification his remark that I have quoted is incorrect: and I think he will see that his supposition that my remarks referred only to a straight bar with free ends, and not to an endless band, is contrary to the expressed terms of my letter. The fact remains that the motion of even an endless band has not necessarily anything to do with the stability of the straight part. Dr. Lodge apparently still wishes us to suppose otherwise.

Devonport, April 12.

A. M. WORTHINGTON.

\section{A Lecture Experiment illustrating the Magnetic Screening of Conducting Media.}

A LECHER's tube (Wied. Ann., xli. p. 85o) is put, by means of two cork rings, into another large $(4 \mathrm{~cm}$. diam.) glass tube, with a crane on one end. Holding the tube in one hand, and approaching it to a wire in which electrical waves are produced, a continuous lighting in the Lecher's tube is to be seen. 'This lighting remains even if the large tube, including the Lecher's tube, is filled with water. But if the tube is filled with dilute sulphuric acid the light disappears.

When we open the crane and the acid hows out, we perceive the light again, but only in that part of Lecher's tube which is not surrounded with the acid. The light in the Lecher's tube penetrates but very little below the level of the acid in the surrounding tube.

St. Petersburg, University, April 14.

J. J. BORGMAN

NO. I I 2 I, VOL. 43]

\section{The Intelligence of the Thrush.}

IT is, I think, well to record the following observations of the intelligence of the thrush. The first happened on June 28 , 1865 . I then saw, from the windows that look out on the little lawn north of my house, a thrush steadily "stepping westward" in front of the hedge that parts the lawn from the public road. The bird seemed to be intentionally making for a gravel path that, after passing almost close to the windows, hends to the north-west, toward the small gate of $\mathrm{my}$ front garden. It was bearing something in its bill. On coming to the path it attempted to break this on a stone. It did not succeed. It then tried another stone. This time it succeeded. Thereupon it flew away. On the spot I found a remarkably big stone embedded in the path, and round it were scattered bits of snail shell. The bird had eaten the snail.

The second of the observations I would note, and the more striking of the two, happened on June 5,1890 . I then was viewing the gravel path from the westernmost of the four windows. Just beneath me, standing on the path, was a female thrush. She had succeeded in breaking a snail shell. She had the snail in her bill. But, despite of vigorous efforts, she could not swallow it. Up hopped a male thrush. Standing before the female, he opened his bill. She dropped the snail into his bill. He chewed the snail. He dropped it back into the female's ready bill. She swallowed it. The pair blithely trotted off, side by side, toward the small gate. I saw them no more.

$$
\text { JOHN HOSKYNS-ABRAHALL. }
$$

Combe Vicarage, near Woodstock, Oxfordshire, April $\mathbf{I} 6$.

\section{Cocks and Hens.}

WHILST I was living at Highfield House in Nottinghamshire in 1879 , a duck-wing game bantam injured her leg after she had been sitting for a fortnight, and could no longer remain on the eggs. The cock bird, however, took her place, and not only hatched the brood, but acted in all respects like a hen, brooding the young, setting his feathers up like a brood hen, and using the same peculiar cluck that a hen has for calling her chickens, also sleeping on the nest instead of his usual perch-being, in fact, a mother for the time. Years before (in $184 \mathrm{I}$ ) one of my Dorking hens was accidentally killed, leaving a brood of chickens some five weeks old ; the Dorking cock took to them and brought them up, but in this instance there was no change except the act of brooding.

Shirenewton Hall, Chepstow, April 12.

\section{Cackling of Hens.}

IT is often difficult to recall an actual instance of what may be a matter of very common occurrence. Such is to a certain extent the case with the subject to which Prof. Romanes's query in NATURE of April 2 (p. 5i6) refers.

In a general way it is my impression that the cackling of jungle fowl is not very commonly heard in India, but I feel certain that I have heard it occasionally, and that I once did hear it upon a somewhat considerable scale is impressed very distinctly upon my memory by certain and special circumstances. My tent for a few days in April 1876 was pitched close to a perfectly impenetrable patch of thorny jungle in Orissa. This cover was full of jungle fowl, and I remember hearing the cackling of the hens, which reminded me of the familiar farm. yard sounds of home. It is possible that in this case the safety of their retreat may have had something to do with their not fearing to cackle with unusual vigour.

Science and Art Museum, April is

\section{THE PARADOX OF THE SUN-SPOT CYCLE} IN METEOROLOGY.

$\mathrm{I}$ I 872 and 1873 , three writers, independently of each other and dealing with different branches of meteorological science, revived an old speculation of Sir William Herschel's, that the sun's heat probably varies with the 
visible changes of its photosphere, and that this variation is sensibly reflected in the meteorology of our planet. Mr. Chas. Meldrum reviewing the statistics of the cyclones of the Indian Ocean, Mr. Norman Lockyer those of the rainfall of Ceylon, Southern India, and Australia, and Dr. Köppen the recorded temperatures of numerous stations in various parts of the world, separately arrived at the conclusion that these three classes of phenomena severally afford evidence of a periodical increase and decrease coinciding with that of the solar spots. The speculation, thus started, was followed up with avidity by a large number of inquirers in different parts of the world. The intensity of the solar radiation, the barometric pressure, the levels of rivers, lakes, and inland seas, and even such more remote effects of meteorological conditions as are manifested in the prices of grain, the recurrence of exceptional vintages, of famines, and in the activity of trade, were all brought under investigation; and, for some years, this and other scientific journals contained frequent articles, bringing to notice some new instance or supposed instance of a recurrent variation conforming more or less accurately to the well-known solar period of eleven years. It must be admitted that some of these supposed coincidences were based on evidence that was far from convincing : and since the major part of the weather phenomena of the globe failed to show any distinct trace of the influence of the solar cycle, interest in the subject gradually declined, and for the last few years the discussion of the question has been comparatively in abeyance.

But anyone who considers carefully the bulk of the evidence brought to light in the course of the inquiry will, I think, be prepared to admit that, amid much that is doubtful and inconclusive, the general result has been to establish so many cases of the variation of certain meteorological elements, coinciding with that of photospheric activity, as to place the general truth of the hypothesis beyond all reasonable doubt; but that the amount of the variation is so small in comparison with the irregular vicissitudes of the weather, that it is for the most part obscured and unrecognizable, except fitfully, or in some few favoured regions where these irregularities are less prominent. This has long been the opinion of the present writer, and a similar view was expressed in no hesitating terms by Prof. Arthur Schuster in 1884 , in a paper read before the meeting of the British Association at Montreal, and printed in their Reports. "There can," he says, "be no longer any doubt that during about four sun-spot periods (1810 to 1860 ) a most remarkable similarity [existed] between the curves representing sun-spot frequency and the curves of nearly every meteorological element which is related to temperature. This is not, in my opinion, a matter open to discussion: it is a fact. But it is equally certain that during the thirty or forty years previously to that time no such relationship existed, and that since 1860 the connection has again in some instances become less distinct."

In so far as regards the temperature of the globe, these conclusions are almost identical with those enunciated by Prof. Köppen, in a paper published in the April-May Heft of the Austrian Meteorological Zeitschrift for I881, and indeed the apparent discrepancy of the temperature and sun-spot curves after 1858 had been indicated by him in his former paper, published eight years earlier. But this discrepancy did not set in simultaneously in different parts of the globe, nor has it been such as to obliterate all trace of the sun-spot cycle in the temperature curves. During about four cycles previous to 1858 , the temperature of the tropical zone rose and fell with somewhat striking regularity inversely as the spotted surface increased or diminished, so that the highest temperatures approximately coincided with the sun-spot minima, and the lowest with their maxima. A similar course of varia- tion, but of less amplitude and more complicated with subordinate disturbances, characterized also the temperate zones during a great part of this period; but in the north temperate zone, after I 856 , these subordinate disturbances gained in relative importance, and although well-marked minima still approximately coincided with the sun-spot maxima of 1860 and 1870 , the intermediate period exhibits a series of oscillations some of which are of not less amplitude than that of the solar cycle. In the south temperate zone, on the other hand, the conformity of the temperature with the [inverted] sun-spot curve continued well marked up to 1870 , but the secondary oscillation, which is also shown by the sun-spot curve, is more strongly reflected in the former; while in the tropics, as far as can be inferred from the evidence of the very few stations that furnish continuous registers for these years, the coincidence began to fail in 1858 , and from 1870 to I 875 the course of the variation appears to have been entirely in disaccord with that of the solar spots.

Now it is in the tropics, and more especially the central equatorial portion of that zone, that we should expect to find evidence of the coincidence if it really exists. It is not only that the solar action is here most intense, but that the influx of the lower atmospheric currents, which are one of the principal agencies that affect and disturb the local "solar" climate, is here most regular, while the alternations of anticyclones and cyclones-the one bringing clear skies and free radiation, the other a cloud canopy and obstructed radiation - are of minor importance, and indeed in the equatorial zone almost evanescent as disturbing causes.

But, as has been already remarked, the stations in the tropics that furnished comparable and continuous registers before 1875 are very few. Up to 1860 they varied from three to twelve for the entire region, and even up to 1875 they were not greatly more numerous. But, since that date, the temperature of India has been recorded with far greater completeness, and it will be interesting, therefore, to inquire how far the ampler evidence thus furnished for at least one tropical country of great extent confirms or invalidates the conclusions drawn from the very defective data of previous years. If we find, as the result of this examination, that the temperature of India as a whole, since 1875 , has followed in its variations from year to year the waxing and waning of the spotted areas of the solar surface, and that with even greater regularity than was shown by the scanty records at Prof. Köppen's disposal for the earlier period, we may then infer with some likelihood that some of the discrepancies shown by his curves really arise from the imperfect elimination of the mere local disturbances which all single registers exhibit, when compared with each other, in a more or less marked degree.

For several years past, the annual reports on the meteorology of India have contained a table showing the deviation of the temperature of the country, as a whole, from its normal or average value, in each suc. cessive year since 1875 ; but this has been computed yearly from the several averages of the stations as known up to date, and as these have been corrected yearly, the standards have varied throughout, and in the earlier years differed from those now accepted by amounts quite appreciable in an investigation of this kind. Moreover, the registers of all the existing stations could not be utilized in the earlier years, their average values being then unknown. In the following table, therefore, the mean annual anomalies have been recomputed from the published registers, taking as a common standard the mean tem!perature of each station given in the report for $\mathrm{I} 888$, and including the registers of all stations in India, Burma, Ceylon, and the adjacent islands, that have furnished a complete or nearly complete register in each year. The results are given in the third column of the table; the

NO. I I 2 I, VOL. 43] 
fourth shows the annual increments or decrements, and the two right-hand columns Wolf's relative sun-spot numbers and their progressive variation.

\begin{tabular}{|c|c|c|c|c|c|}
\hline \multirow{2}{*}{ Year. } & \multirow{2}{*}{ Stations. } & \multicolumn{2}{|c|}{ Temperature $\left({ }^{\circ} \mathrm{F}.\right)$} & \multicolumn{2}{|c|}{ Sun-spot number. } \\
\hline & & $\begin{array}{l}\text { Annual } \\
\text { anomaly. }\end{array}$ & Prog. var. & Annual. & Prog. var. \\
\hline I 875 & 75 & 0 & - & $17 \cdot 1$ & $-27 \cdot 5$ \\
\hline 1876 & $8 \mathrm{I}$ & $+0.2 \pi$ & +0.21 & I I 3 & -5.8 \\
\hline 1877 & 90 & +0.40 & +0.19 & $12 \cdot 3$ & $+\mathrm{r} \cdot \mathrm{O}$ \\
\hline 1878 & 102 & +0.84 & +0.44 & 34 & $-8 \cdot 9$ \\
\hline I 879 & ro7 & +0.02 & -0.82 & 6.0 & $+2 \cdot 6$ \\
\hline 1880 & 107 & +0.37 & +0.35 & $3 I \cdot 5$ & +255 \\
\hline 1881 & 112 & +0.29 & -0.08 & 54.2 & $+22 \cdot 7$ \\
\hline 1882 & 107 & +0.10 & -0.19 & $59^{\circ} 6$ & +54 \\
\hline 1883 & I J 8 & -0.30 & -0.20 & 63.7 & $+4^{1} 1$ \\
\hline 1884 & I 14 & -0.56 & -0.26 & 63.4 & -0.3 \\
\hline 1885 & 120 & -0.26 & +0.30 & $52 \cdot 2$ & $\sim 1 \mathrm{I} \cdot 2$ \\
\hline 1886 & 120 & +0.10 & +0.36 & 25.7 & $-26 \cdot 5$ \\
\hline I 887 & 127 & -0.20 & -0.30 & $13 \cdot 1$ & -12.6 \\
\hline I 888 & 127 & +0.36 & +0.56 & $6 \cdot 7$ & $-6 \cdot 4$ \\
\hline $1889^{1}$ & 29 & +0.70 & +0.34 & $5 \cdot 8$ & -0.9 \\
\hline
\end{tabular}

From this table it appears that, except in the two anomalous years 1879 and I887, the temperature of India, \&c., as a whole, has followed with remarkable regularity the course of the sun-spot variation; the maximum temperature occurring in 1878 , the year of the sun-spot minimum, and the minimum temperature in I 884, in which the spots were almost as numerous as in the preceding year of their maximum. If the figures of column 3 be smoothed by the same process as was applied by Köppen to those of the years antecedent to I 860 , it will be found that when laid down graphically the resulting curve corresponds to the inverted sun-spot curve more closely than in any antecedent period. Thus treated they are as follows :-

$\begin{array}{llc}\text { I875 } & \ldots & - \\ \text { I876 } & \ldots & +0.2 \mathrm{I} \\ \text { I877 } & \ldots & +0.46 \\ \text { I878 } & \ldots & +0.53 \\ \text { I } 879 & \ldots & +0.31 \\ \text { I } 880 & \ldots & +0.26 \\ \text { I } 881 & \ldots & +0.26\end{array}$

$\begin{array}{lll}\mathbf{I} 882 & \ldots & +0.05 \\ \mathbf{I} 883 & \ldots & -0.27 \\ \mathbf{I} 884 & \ldots & -0.42 \\ \mathbf{I} 885 & \ldots & -0.25 \\ \mathbf{I} 886 & \ldots & -0.06 \\ \mathbf{1} 887 & \ldots & +0.13 \\ \mathbf{I} 888 & \ldots & +0.30\end{array}$

The amount of the oscillation during this cycle, appears to have been about $I^{\circ} \mathrm{F}$., and is about the same as the average of the four cycles antecedent to 1860 as shown by Prof. Köppen's figures.

So far, then, from there being any reason to conclude that the meteorology of our planet since 1860 has ceased to display that direct influence of the solar cyclical variation that was so marked during the preceding half century, it appears that when ample evidence is forthcoming, and in that region where the sun's effect is most direct and intense, being at the same time least exposed to casual disturbance, that influence is displayed as strongly as ever, and it seems highly probable that the apparent discrepancy in tropical regions adverted to by Profs. Köppen and Schuster is to be in great part attributed to the imperfection of the data at their command.

Of all atmospheric conditions, the temperature is the most direct and immediate effect of the sun's heat, and therefore the most likely to afford indication of any variation in the intensity of that heat. But the element which, in this connection, more than any other, has engaged the attention of meteorologists, is the rainfall;

The temperature of this year is taken from a preliminary report, received
from India since this article from India since this article was written. 1889 appears to have been a year of maximum temperature probably, as it was also the year of sun-spot
minimum.

NO. I I 2 I, VOL. 43$]$ and it is their general failure to obtain any distinct confirmation of the influence of the solar cycle in the annual variation of the rainfall, that perhaps, more than aught else, has tended to bring the whole hypothesis into discredit. But there are very good reasons why such inquiries should fail. No meteorological element is more subject to purely local variation, or is more largely influenced by what, in our ignorance, we must term the casual and irregular movements of the atmosphere ; and yet most meteorologists have been content to summarize the results of single stations or of a few stations widely scattered, and to accept them as representative of enormous areas. How erroneous and misleading such assumptions must necessarily be, may be proved by anyone who will take the trouble to discuss the annual distribution of the rainfall of any European country well furnished with rain-gauge stations, or, still better, that of any extensive region, such as the United States or the Indian Empire; and he will find that, in any given year, there is no uniform excess or deficiency throughout, but while some districts, states, or provinces have received more than an average amount, others are in defect of the average.

If, for the sake of argument, we may assume that the influence of the sun-spot cycle has been conclusively established in the case of the temperature of the tropics, it follows necessarily that it must also hold good, though, perhaps, with diminished intensity, in every other kind of meteorological condition and in all parts of the world; but it may well be that the effect is so small, that in the higher latitudes it can only be detected on the average of many cycles, and when the simultaneous condition of the whole temperate zone, for instance, can be brought under review. For the present we may restrict our attention to the tropics.

That the rainfall of the Indian Empire, as a whole, exhibited no regular periodic variation during the 22 years I 864-85, I have shown elsewhere. But to this the Carnatic province, comprising the whole of the great plain in the south-east of the peninsula, affords an apparent somewhat striking exception, to which attention was drawn in NATURE, vol. xxxvi. p. 227. It was the rainfall of this tract, or rather of its chief city, Madras, that furnished one of the instances adduced by Mr. Lockyer, in the paper already referred to at the beginning of this article. From the results of the twenty-two years, comprising, therefore, two complete solar cycles, it appeared that, with a general average of only 35 inches for the whole province, a variation of no less than 14 inches took place between the years of maximum and minimum on the mean of the two cycles, even when the amounts actually recorded had been reduced to the terms of a harmonic series. Whether this remarkable oscillation will be found to hold good in future cycles, I will not venture to speculate; but it must be confessed that it seems extremely disproportionate to the temperatureoscillation, the magnitude of which rests on a far more extensive basis.

The Carnatic is the most southern lowland of the Indian peninsula, and therefore perhaps more favourably situated for displaying the direct effect of any variation of the solar heat than most other parts of the Empire, but it is by no means beyond the influence of the dry winds, the unseasonable incursion of which, I have elsewhere shown to characterize years of drought, as is also the case in Northern India. Ceylon, the southernmost portion of which lies within the equatorial zone of comparatively uninterrupted rainfall, is still more advantageously situated; but undoubtedly the region that holds out the best promise of deciding the question of rainfall periodicity, in the present case, is the Eastern Archipelago, in which the network of rain-gauge stations established by the late Dr. Bergsma, has already furnished data for thirteen years, and should therefore in the course of a 
few years more afford materials sufficient, at all events, for a preliminary inquiry into the subject.

Meanwhile, it will be asked "Why,-instead of seeking for evidence in these by-ways of atmospheric action and reaction, where, at best, we can but hope to detect some remote and distorted reflection of the varying phases of the primary agent-why do we not appeal at once to the fountain head, and put the question to that very radiant heat which is the prime motor, the law of whose variations we are endeavouring to discover?" The obvious reply is that such a course is at present impracticable. So great and at the same time so variable is the atmospheric absorption, that the attempts that have been made to determine the calorific intensity of the sun's rays on the exterior of our atmosphere-the quantity termed, as if in mockery, the solar constant-give values differing so greatly according to the state of the atmosphere, that it is hopeless to detect in them with any certainty a variation so small as that indicated by the temperature oscillation. The only continuous actinometric register as yet carried out is that of M. Crova at Montpellier since I883. I have not seen any reduction of his results for the determination of the so-called solar constant in different years, but the variations of the mean measured intensity on clear days from year to year are very irregular, and the mean of 1883 exceeds that of 1887 by not less than I 2 per cent.

The more popular instrument, the sun thermometer, is still more unsatisfactory. While it is affected by obscure atmospheric changes equally with the actinometer, it is also influenced by every change in the surrounding objects, and by the wind, and the instrument itself is so uncertain that it is hard to find two that read alike. Many of them also are subject to a gradual deterioration that renders their earlier and later registers no longer comparable. Only in the few rare cases, where one and the same invariable instrument has been observed on the same spot, with the same entourage, during many years in succession, can any valid comparison be made between the values of successive years, and owing to the great fragility of these thermometers and the difficulty of adequately protecting them, such records are very rare. One such register was obtained by the late Prof. S. A. Hill at Allahabad during the ten years $1876-85$, and the results were very carefully discussed by him, and, as far as possible, corrected for the varying absorption of the atmosphere due to the several elements, dry air, water vapour, and suspended dust. The mean result, in terms of the corrected insolation readings (i.e. the excess of the equilibrium temperature of the instrument over the temperature of the surrounding atmosphere), was thus found to be as follows in each year :-

\begin{tabular}{|c|c|c|c|c|}
\hline 1876 & $\ldots$ & $82^{\circ} \cdot 8$ & I 88 I & \\
\hline I877 & $\ldots$ & 85.1 & 1882 & $\ldots$ \\
\hline 1878 & $\ldots$ & $85^{\circ} 2$ & I 883 & $\ldots$ \\
\hline 1879 & $\ldots$ & $83 \cdot 6$ & 1884 & $\ldots$ \\
\hline 1880 & $\ldots$ & $82 \cdot 7$ & 1885 & $\ldots$ \\
\hline
\end{tabular}

The cyclical variation shown by these figures is identical in character with that of the air temperature of India as a whole, the maximum being in 1878 , the minimum in I883, which were respectively the years of minimum and maximum sun-spots, but, as might be expected, the oscillation is much greater. Even when the range is somewhat reduced by the smoothing process already applied to the temperature records, it amounts to five and a half times as much as that of the air temperature in the same period. From the nature of the observations, however, no great stress can be laid on this fact.

We now come to what may be termed the paradox of the whole problem. We have seen that both the air temperature and that of insolation seem to testify unmistakably to the fact that the sun's heat is greatest when his surface is least spotted, and vice versá. But the evidence of the spectroscope points in a diametrically opposite direction, and so also do Meldrum's and Poey's statistics of the frequency of tropical cyclones, and, as far as it goes, the more dubious evidence of the rainfall, since, in all cases in which any appearance of a periodical variation has been detected, the rainfall is most abundant about or shortly after the epoch of maximum sun-spots, and least about the years of minimum, implying therefore increased evaporation and an increased movement of the atmosphere at the former epoch. The variation of the barometric pressure which has been detected in the Indo-Malayan region on the one hand, and in Western Siberia and Russia on the other, also seems to show that in years of maximum sun-spots a larger portion of the tropical atmosphere is transferred to high latitudes in the winter hemisphere, which again implies an increased disturbance of atmospheric equilibrium at that epoch between the tropics and the circumpolar zone, and therefore an increased intensity of the disturbing agent.

I must content myself with pointing out this discrepancy without attempting to explain it. It does not necessarily invalidate the evidence of either class of facts, since there may possibly be causes at work, which, when known, will be found to reconcile the apparent inconsistency; but it should assuredly act as a stimulus to our efforts to extend our basis of facts, in full confidence that all inconsistency will eventually disappear.

Before concluding this summary, I must briefly notice a very important investigation of Prof. Hann's, which, at first sight, might seem to negative the whole hypothesis of a cyclical variation of the solar heat; though such a conclusion would be by no means legitimate, and, in point of fact, is not put forward by its author. It was shown by Lamont that, when the diurnal double oscillation of the barometer is analyzed into its two chief constituents, viz. a wave of diurnal and two of semi-diurnal period, while the former varies very greatly in character and magnitude with the geographical conditions of a place, the latter is almost unaffected by these conditions, except that its amplitude decreases the higher the latitude. Assuming that this semi-diurnal tide is a direct effect of the sun's rays absorbed by the higher strata of the atmosphere, Dr. Hann examined the registers of the hourly observations of the barometer at Bombay, Batavia, and Vienna from I 847 to I862, to see whether the amplitude of this element of the oscillation showed any appreciable increase and decrease corresponding to the phases of the sun-spot cycle. The result was that no such variation was to be detected. The fundamental assumption here made, that the magnitude of this double oscillation should vary with the quantity of heat absorbed by the atmosphere, was verified in a subsequent elaborate memoir, in which it was shown that at the time of perihelion, when our planet receives one-fifteenth more heat than at aphelion, the amplitude of the semi-diurnal tide is, on an average, as much as one-tenth greater-an exaggeration of the effect which Dr. Hann attributes to secondary meteorological actions. In any case, the result satisfies the logical conditions of the inquiry.

Now, accepting Dr. Hann's conclusion that "the heat absorbed by the atmosphere does not vary considerably [erheblich] with sun-spot frequency," it remains to inquire whether, taking as our standard the amount of the temperature variation deduced by Köppen, and substantiated by the later Indian registers, the effect to be expected is of such magnitude as would be readily rendered evident in the amplitude of the semi-diurnal wave of pressure. There is no reason to suppose that it would bear a greater ratio to the total pressure effect than does the temperature increment during the sun-spot cycle to the total effect of the sun's rays on the temperature of our atmosphere. What the temperature of our earth would be, in the absence of the sun, we do not indeed know. But we shall probably be well within reasonable limits if we

NO. I I 2 I, VOL. 43 ] 
assume that it would be at least $100^{\circ}$ below the zero of Fahrenheit's scale, or $180^{\circ}$ below the actual mean temperature of the tropics. Of course, under such circumstances, the temperature of the tropics would be no higher than that of the Poles. Making this assumption, then, the oscillation of the temperature during the course of the sun-spot cycle is only I/I 80 of the total effect. Now the amplitude of the semi-diurnal element of the barometric oscillation at Batavia (the most equatorial of the three stations) is $1.896 \mathrm{~mm}$., or 0.0746 of an inch, and the $1 / 180$ part of this is $0^{\circ} 0004$ inch-a quantity that would be quite inappreciable in an investigation of this kind, masked as it must be by the much larger irregular variations shown by the register. It does not seem, then, that Dr. Hann's negative results really affect the validity of the positive evidence already afforded by other meteorological phenomena, and need not discourage us in our endeavours to obtain an explanation of the paradox indicated above, which, to my mind, is the most interesting feature of the problem. HENRY F. BLANFORD.

\section{THE QUESTION OF THE ASTEROIDS.}

$\mathrm{I}^{\mathrm{T}}$

has already been noted that the editors of the Berliner Fahrbuch have decided only to issue ephemerides for certain of the minor planets (NATURE, vol. xliii. p. III). The Bureau des Longitudes has endeavoured to remedy the inconvenience that arises from this decision by an extension of one of its departments. The general discussion that led the Bureau to adopt this course, and the importance of observations of these comparatively small bodies, are well expounded by M.F. Tisserand in the Annuaire for I89I.

Kepler recognized the continuity of the mean distances of the planets from the sun, when he said : "Infra Martem et Jovem novum interposui planetam." The publication of Bode's empirical law in I772 confirmed Kepler's ideas, and fixed the distance of the hypothetical planet as $2 \cdot 8$ times the mean distance of the earth from our luminary. But the existence of such a planet appeared still more probable when the calculations of Lexell and Laplace had shown that the magnitude of the orbit of the planet Uranus, discovered by Sir William Herschel in $\mathrm{I} 78 \mathrm{I}$, might have been predicted with accuracy from this relation between planetary distances. At a Congress held at Gotha in I796, it was proposed to search for the unknown body, and twenty-four astronomers each undertook the examination of an hour of the zodiac. The discovery of Ceres by Piazzi on January I, I80I, almost before the association of observers had got fairly to work, is a matter of common knowledge. Gauss's calculations showed that the mean distance of this planet from the sun is 277 , which corresponds with that indicated by Bode's law; hence the gap appeared to be filled, but by a body of very modest size, for the measures made by Herschel only assign it a diameter of about I 55 miles.

Olbers's discovery of a second planet, Pallas, moving round the sun at the same mean distance as Ceres, gave the question another aspect. It was proved by Gauss that the two bodies may pass very near to each other at two points situated on the line of intersection of the planes of their orbits. This led Olbers to oelieve that the new planets were portions of a larger body broken up by some internal disturbance, and he accordingly suggested that other fragments might be found near the points of intersection of their orbits. The hypothesis was supported by Harding's discovery of Juno in 1804 , near one extremity of the line of intersection, and the discovery of Vesta by himself in 1807 , close to the other extremity.

It was not until i 845 that a fifth planet was discovered by Encke, and this was even smaller than the four that preceded it. After this date the discoveries became more frequent, and now the number has reached 308 . But the magnitudes of the newly-discovered bodies are decreasing, for, whilst the first four have magnitudes comprised between 6 and 8, the two discovered by Encke are only of the 9 th magnitude, and those now found are rarely brighter than the $13^{\text {th }}$ magnitude.

The hypothesis advanced by Olbers as to the origin of the asteroids - a designation due to Herschel-has not found much support. Newcomb, from an investigation of the orbits of the first forty asteroids, found that their planes are far from having a common line of intersection. It may be suggested that this geometrical condition was fulfilled at a certain epoch, and that the perturbations caused by Jupiter and Saturn have caused the present distribution. Calculations show, however, that the required condition never existed; hence Olbers's hypothesis must be abandoned.

With regard to the width of the zone which contains the orbits of the asteroids, we find that (149) moves round the sun at the shortest mean distance, viz. $2 \cdot 13$, and that (279), the asteroid most removed from our luminary, has a mean distance of $4^{2} 26$. The periods of revolution of these two bodies are, respectively, 3.11 and 8.81 years. It will therefore be seen that the asteroids revolve in orbits much greater and less than that assigned by Bode's law.

When the eccentricities of the orbits are considered, it is found that (132) may approach to a distance of $I .6 I$ from the sun, whilst $(17$ may get so far away as 4.73 times the earth's mean distance. The asteroids are, therefore, contained in a wide zone, and the whole of their positions form a kind of ring having a radius a little more than three times the distance of the earth from the sun.

If the asteroids are arranged into groups, of which the eccentricities are comprised between limits differing by 0.05 , the following result is obtained :-

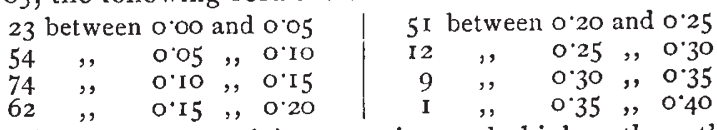

The mean eccentricity, 015 , is much higher than the corresponding mean of the major planets-viz. 0.86 . It appears, therefore, that some notable differences must have existed in the conditions of formation.

But the difference is still more striking in the case of the inclinations of the orbits. The mean inclination is $8^{\circ}$, which is slightly greater than that of Mercury and that of the sun's equator. Of 293 asteroids, 17 have inclinations greater than $20^{\circ}$. These are given in the following table, and also their eccentricities and mean distances:-

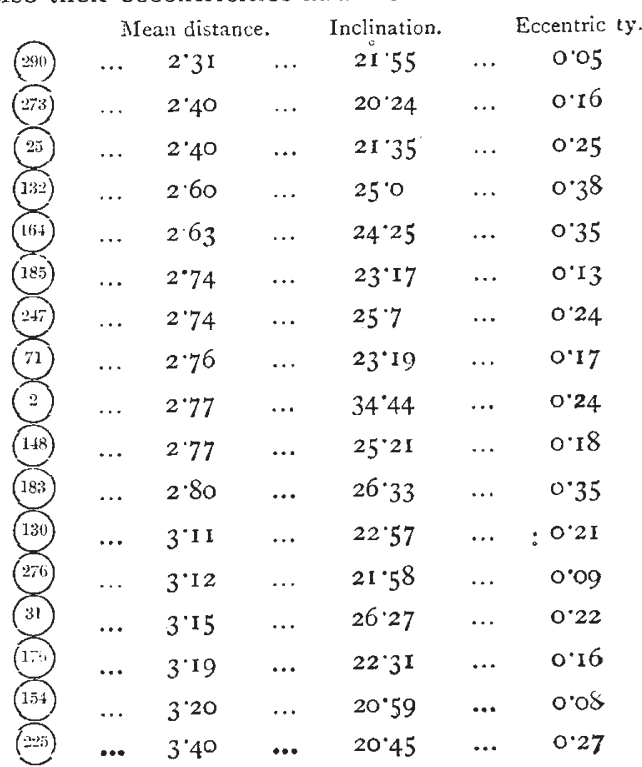

NO. I 12 I, VOL. 43 ] 